\title{
Frequency of Retinoblastoma at Lady Reading Hospital, Peshawar, Pakistan
}

\author{
Zafar Iqbal, Tariq Muhammad Saeed \\ Department of Ophthalmology, Postgraduate Medical Institute, Govt Lady Reading Hospital, \\ Peshawar, Pakistan
}

\begin{abstract}
Aim: To ascertain the demographics, clinical features, and treatment options for children with retinoblastoma. Methods: This was a hospital-based cohort study of all children with retinoblastoma presenting from 1 January 2008 to 31 December 2008. Demographic data, presenting features, family history, and findings identified during examination were recorded for each patient. The tumours were classified using the ReeseEllsworth classification system. Documentation of the tumours included examination under anesthesia, ultrasound B-scan, and computed tomography scan as well as histopathological reporting of enucleated eyes. Results: Twenty seven new patients with retinoblastoma were identified and 36 eyes were affected, with a bilaterality rate of $33 \%$. The frequency was 4.1, with a bimodal peak of presentation of younger than 1 year and 4 years. The mean age at diagnosis was 3.2 years (SD, 2.5 years; range, 3 months to 8 years). Most of the patients were boys, (59\%) and most were in the age range of 1 to 5 years (66\%). There was a male preponderance (5:1) amongst patients younger than 1 year and the male to female ratio was equal (1:1) in the 1 to 5 years age range. Leukocoria was the main presentation in 38\% of eyes and 19\% presented with proptosis. Enucleation/exenteration was performed for 17 unilateral eyes (94\%) and 5 bilateral eyes $(27 \%)$ with group $V$ disease. Groups I and II tumours $(n=1$ and $n=7$ for unilateral and bilateral eyes, respectively) were treated conservatively with cryotherapy or chemotherapy alone or in combination. The commonest treatment for bilateral disease was enucleation of 1 eye and chemotherapy for the fellow eye (22\%). Radiotherapy was advised for patients with histopathological evidence of optic nerve involvement (25\%).

Conclusions: Retinoblastoma usually affects infants and children younger than 5 years, with no sexual or racial predilection. One-third of patients demonstrate bilaterality, with leukocoria as the commonest presenting feature and proptosis as a feature of late presentation. In bilateral retinoblastoma, primary enucleation of one eye with conservative chemotherapy and/or cryotherapy of the fellow eye is advocated.
\end{abstract}

Key Words: Cryotherapy, Drug therapy, Eye enucleation, Exophthalmos, Radiotherapy, Retinoblastoma

Asian J Ophthalmol. 2011;12:140-3.

\section{Introduction}

Retinoblastoma is the most common primary cancer of the eye in children, ${ }^{1}$ representing $4 \%$ of childhood cancers and less than $1 \%$ of all cancers. Retinoblastoma may affect boys and girls equally, with no racial predilection. Either eye may be affected and bilaterality is present in $30 \%$ to $40 \%$ of patients. ${ }^{2}$

The incidence varies from country to country and is between 1 in 15,000 and 1 in 20,000 live births. ${ }^{3}$ Approximately 250 to

Correspondence: Dr Zafar lqbal, Department of Ophthalmology, Postgraduate Medical Institute, Govt Lady Reading Hospital, Peshawar, Pakistan.

Tel: (92 91) 256 0070;

E-mail: dr_ziqbal@yahoo.com
300 patients are newly diagnosed each year in the USA, ${ }^{4}$ and worldwide estimates are 5000 new patients each year. ${ }^{5}$

Leukocoria and strabismus are the 2 most frequent initial presentations of retinoblastoma. Other presenting features include orbital inflammation, proptosis, uveitis, and retinal detachment. Sixty per cent of retinoblastomas are unilateral and most of these are non-hereditary (the median age at diagnosis is 2 years). Retinoblastoma is bilateral in $40 \%$ of patients (the median age at diagnosis is 1 year). All bilateral and multifocal unilateral forms are hereditary.

Examination under anesthesia aids the diagnosis and management of retinoblastoma. Enucleation is often necessary for unilateral disease; the decision for adjuvant treatment is 
taken according to the histological risk factors. Conservative treatment for at least 1 eye is possible for most bilateral disease. Treatment includes cryotherapy, ${ }^{6-8}$ either alone or combined with chemotherapy. Long-term follow-up and early counseling about the risk of second primary tumours and transmission should be offered to parents of patients with retinoblastoma.

This study was performed to ascertain the demographics, clinical features, and treatment options for children with retinoblastoma in Pakistan.

\section{Methods}

The study was a hospital-based cohort series of children with retinoblastoma admitted to the Department of Ophthalmology, Lady Reading Hospital, Peshawar, Pakistan, from 1 January 2008 to 31 December 2008.

All new patients presenting with retinoblastoma during this period were enrolled in the study. A form was designed and completed prospectively for each patient, and demographic data, presenting features, detailed family history, and results of examination under anesthesia of each patient were recorded. The tumours were classified using the Reese-Ellsworth classification system. ${ }^{9,10}$ Baseline investigations were performed and the extent of disease was documented by examination, B-scan ultrasonography, and computed tomography scan.

All new patients with retinoblastoma were enrolled in the study, including those lost to follow-up and those leaving against medical advice (LAMA). Children who had been diagnosed in previous years and were already receiving treatment were excluded.

Management options included enucleation, exenteration or partial exenteration, cryotherapy, chemotherapy, and radiotherapy. Chemotherapy involved a triple-regimen of vincristine, etoposide,

Table 1. Age and sex distribution of patients with retinoblastoma $(n=27)$.

\begin{tabular}{|lllll|}
\hline \multirow{2}{*}{ Sex } & \multicolumn{3}{c|}{ Age range (years) } & Total (\%) \\
\cline { 2 - 4 } & \multicolumn{1}{c}{$\mathbf{1}$} & $\mathbf{1 - 5}$ & $\mathbf{> 5}$ & \\
\hline Boys & 5 & 9 & 2 & $16(59)$ \\
Girls & 1 & 9 & 1 & $11(41)$ \\
Total (\%) & $6(22)$ & $18(67)$ & $3(11)$ & $27(100)$ \\
\hline
\end{tabular}

and carboplatin ${ }^{11-17}$ given in 3- to 4-week cycles for 6 cycles. ${ }^{18,19}$ Radiotherapy was advised for patients with histological evidence of extraocular and trans-scleral extension, inadequate resection, and those whose histological reports were inconclusive.

\section{Results}

The unit admitted 27 new patients with retinoblastoma during the study period, for an average of 2.25 patients per month. The frequency was $4.1 \%$ of all children admitted to the department $(n=647)$, with a bimodal peak of presentation of younger than 1 year and 4 years. The mean age at diagnosis was 3.2 years (SD, 2.5 years; range, 3 months to 8 years).

The annual crude incidence was $0.86 / 100,000$. Most patients were boys (59\%) with most aged 1 to 5 years $(67 \%)$. There were more boys than girls (5:1) amongst patients younger than 1 year and the male to female ratio was equal $(1: 1)$ in the 1 to 5 years age range. The patients' characteristics are shown in Table 1.

Bilaterality was present in one-third of patients (33\%); 36 eyes were affected. Three patients ( 1 bilateral and 2 unilateral) were lost to LAMA and 5 ( 3 bilateral and 2 unilateral) were lost to follow-up.

Fourteen eyes (39\%) presented with leukocoria and 7 (19\%) presented with proptosis; the demographic data are shown in Table 2. All of the children with proptosis died.

There were 8 eyes (22\%) with groups I to IV disease and 22 eyes $(61 \%)$ with group $V$ disease; the remaining 6 eyes were lost to follow-up. Some of the eyes could not be assessed due to loss to follow-up or LAMA.

Enucleation/exenteration was performed for $13(72 \%)$ and 5 (27\%) unilaterally and bilaterally affected eyes with group V disease, respectively; the remaining 4 eyes were lost to followup (Table 3). Eyes with groups I and II tumours (1 unilateral; 7 bilateral) were treated conservatively with either cryotherapy or chemotherapy, alone or in combination. The most common treatment for bilateral disease was enucleation of 1 eye and conservative chemotherapy for the fellow eye (22\%). Radiotherapy was recommended for eyes with histopathological evidence of optic nerve involvement (25\%).

Table 2. Age and sex distribution of patients with leukocoria and proptosis $(n=21)$.

\begin{tabular}{|c|c|c|c|c|c|}
\hline \multirow[t]{2}{*}{ Sex } & \multirow[t]{2}{*}{ Presenting Feature } & \multicolumn{3}{|c|}{ Age range (years) } & \multirow[t]{2}{*}{ Total (\%) } \\
\hline & & $<1$ & $1-5$ & $>5$ & \\
\hline \multirow[t]{2}{*}{ Male } & Leukocoria & 5 & 6 & 0 & $11(30)$ \\
\hline & Proptosis & 1 & 1 & 0 & $2(5)$ \\
\hline \multirow[t]{2}{*}{ Female } & Leukocoria & 0 & 2 & 1 & $3(8)$ \\
\hline & Proptosis & 0 & 5 & 0 & $5(14)$ \\
\hline Total (\%) & & $6(29)$ & $14(67)$ & $1(5)$ & $21(100)$ \\
\hline
\end{tabular}


Table 3. Management of eyes with retinoblastoma $(n=36)$.

\begin{tabular}{lc|} 
Procedure & Number \\
\hline Enucleation only & 7 \\
Enucleation, chemotherapy, and radiotherapy & 8 \\
Chemotherapy only & 2 \\
Exenteration only & 1 \\
Exenteration, chemotherapy, and radiotherapy & 1 \\
Partial exenteration only & 1 \\
Cryotherapy only & 0 \\
Cryotherapy and chemotherapy & 4 \\
\hline
\end{tabular}

\section{Discussion}

Globally, retinoblastoma is a rare neoplasm, but it remains the most common ocular malignancy in children worldwide. ${ }^{1}$ This is also the case for South Asia. The frequency of retinoblastoma in this study was 4.1 ( 1 in 24 children admitted to the unit; $n=647$ ), with 2.25 new cases per month. Geographic variation in incidence has been reported worldwide and within regions of a country. ${ }^{20}$ The incidence of retinoblastoma was estimated to be 0.86 per 100,000 population in this study, which is comparable with the low-risk regions of the world, although there is the possibility of underreporting. The highest rates are reported from Uganda $(2.9 / 100,000$ men; 2.8/100,000 women) and Zimbabwe (2.2/100,000 men; $3.3 / 100,000$ women). ${ }^{21}$ Bhurgri et al observed an incidence of ocular malignancy of $0.9 / 100,000$ in both Karachi and Quetta, which is comparable with this study. ${ }^{20}$ Although there was a male prediliction in this study, this finding was incidental, and there are no countrywide data for Pakistan.

The frequency distribution in this analysis was bimodal with a peak in presentation of younger than 1 year and another peak at 4 years. The mean age at diagnosis in the USA is 2.5 years, whereas in this study, it was 3.2 years (SD, 2.52 years). The same trend of late presentation was reported by Bhurgri et al in a 5-year study of 101 children registered at the Karachi cancer registry; ${ }^{22}$ The mean age was 3.96 years for boys and 3.85 years for girls.

Unilateral retinoblastoma accounts for $60 \%$ to $70 \%$ of cases, and bilateral disease represents $30 \%$ to $40 \%$ of cases. ${ }^{2}$ A study from the USA found that the ratio of unilateral $(71.9 \%)$ and bilateral (26.6\%) disease has remained stable for the past 30 years, ${ }^{23}$ while a Brazilian study reported a bilateral disease rate of $50 \% .{ }^{24}$ This study reported a rate of $33 \%$ for bilateral disease.

Leukocoria was a presenting feature in $39 \%$ of eyes and is the leading symptom in most reported series. ${ }^{25}$ Proptosis was present in $19 \%$ of eyes with retinoblastoma. Proptosis is a late presenting feature and is rare in developed countries. A Brazilian study reported a proptosis rate of $14 \%$ in a cohort of 28 patients, ${ }^{24}$ which is similar to this study. Only one patient presented with unilateral strabismus, which is in contrast to developed countries where strabismus is the second most common presenting feature.
Tumours involving the fovea result in early loss of vision, causing the eye to deviate. Patients with strabismus tend to present early as it is a disfiguring sign and is noticed easily by the parents. Due to the late presentation in this study, it is probable that some patients with proptosis had a deviated eye at some stage during the course of the disease.

The primary aim of retinoblastoma treatment is preservation of the patient's life, whereas the secondary aim of conservative treatment is preservation of the globe and preservation of at least 1 eye with functional vision for patients with bilateral disease.,226 Treatment is designed to strike a safe balance between both aims, especially for patients with bilateral disease.

Eyes with advanced (group IV and V) unilateral disease and no prospects of useful vision were not eligible for conservative treatment. This included $17(94 \%)$ of the unilateral cases in this study. Consequently, most $(n=13 ; 72 \%)$ had the affected eye enucleated/exenterated. For 4 children (22\%) the disease was fatal due to intracranial or extracranial extension and 2 who were lost to follow-up were presumed to have died. A similar enucleation rate was also seen for bilateral disease due to the late presentation and is a typical finding in developing countries. Similar results are reported in a Brazilian study, where $93.3 \%$ of eyes were enucleated. ${ }^{24}$ Imhof et a ${ }^{27}$ reported that only $9 \%$ and $3 \%$ of 17 children in the Netherlands were in groups IV and V, respectively, and only $5.9 \%$ of eyes were enucleated; all the others were treated with local or conservative therapies. Thus, advanced disease at presentation and the older age of the patients were associated with the need for enucleation. ${ }^{28}$

Bilateral disease shows asymmetrical involvement, with 1 eye usually having more advanced disease. If there is no potential for useful vision, common practice is to enucleate the eye with more advanced disease and to treat the fellow eye with conservative treatment such as cryotherapy, ${ }^{6-8}$ and chemotherapy. ${ }^{11-17}$ In this series, 5 eyes (27\%) with group V disease required enucleation, whereas the fellow eyes (1 in group la and 4 in group llb) were treated conservatively. Three of these children retained good vision, while 1 had macular involvement at presentation and 1 was lost to follow-up and presumed dead. Only 1 child with group llb disease (2 eyes) had both eyes preserved and retains good vision. In total, 6 eyes (33\%) of patients with bilateral disease were preserved with good vision compared with $1(6 \%)$ with unlateral disease.

This study has several limitations in that, of the 36 eyes (18 unilateral; 18 bilateral), 12 eyes were lost from the study population. This included 4 patients with unilateral disease and 4 with bilateral disease. Some parents refused treatment or chose to have a second opinion despite counseling. Some patients were lost to follow-up. The reason for this is multifold and includes lack of awareness by 
the parents of the level of morbidity and mortality involved, lack of resources, or a consequence of the present sociopolitical upheaval in the region.

In conclusion, modern conservative methods of treatment for retinoblastoma give a real chance for preservation of not only the patient's life but also the eye and its vision, provided that an effort is made for early diagnosis. Parent education about the disease, treatment protocols, and regular follow-up is the cornerstone for successful treatment.

\section{References}

1. Abramson DH, Schefler AC. Update on retinoblastoma. Retina. 2004;24:828-48.

2. Sanders BM, Draper GJ, Kingston JE. Retinoblastoma in Great Britain 1969-1980: incidence, treatment and survival. $\mathrm{Br} J$ Ophthalmol. 1988;72:576-83.

3. Murphree AL, Samuel MA, Harbour JW, Mansfield NC. Retina. In: Ryan SJ, editor. Retinoblatoma. 3rd ed. St Louis: Mosby-Year Book, Inc; 2006. p 568.

4. Tamboli A, Podgor MJ, Horm JW. The incidence of retinoblastoma in the United States: 1974 through 1985. Arch Ophthalmol. 1990; 108:128-32.

5. Shields CL, Shields JA. Diagnosis and management of retinoblastoma. Cancer Control. 2004;11:317-27.

6. Shields JA, Shields CL, De Potter P. Cryotherapy for retinoblastoma. Int Ophthalmol Clin. 1993;33:101-5.

7. Tolentino FI, Tablante RT. Cryotherapy of retinoblastoma. Arch Ophthalmol. 1972;87:52-5.

8. Wilson TW, Chan HS, Moselhy GM, Heydt DD, Frey CM, Gallie BL. Penetration of chemotherapy into vitreous is increased by cryotherapy and cyclosporine in rabbits. Arch Ophthalmol. 1996; 114:1390-5.

9. Murphree AL. Intraocular retinoblastoma: the case for a new group classification. Ophthalmol Clin North Am. 2005;18:41-53.

10. Reese $A B$, Ellsworth RM. The evaluation and current concept in retinoblastoma therapy. Trans Am Acad Ophthalmol Otolaryngol. 1963;67:164-72.

11. Murphree AL, Villablanca JG, Deegan WF 3rd, et al. Chemotherapy plus local treatment in the management of intraocular retinoblastoma. Arch Ophthalmol. 1996;114:1348-56.

12. Levy C, Doz F, Quintana E, et al. Role of chemotherapy alone or in combination with hyperthermia in the primary treatment of intraocular retinoblastoma: preliminary results. Br J Ophthalmol. 1998; 82:1154-8.
13. Gombos DS, Kelly A, Coen PG, Kingston JE, Hungerford JL. Retinoblastoma treated with primary chemotherapy alone: the significance of tumour size, location, and age. $\mathrm{Br} \mathrm{J}$ Ophthalmol. 2002;86:80-3.

14. Friedman DL, Himelstein B, Shields CL, et al. Chemoreduction and local ophthalmic therapy for intraocular retinoblastoma. J Clin Oncol. 2000;18:12-7.

15. Beck MN, Balmer A, Dessing C, Pica A, Munier F. First-line chemotherapy with local treatment can prevent external-beam irradiation and enucleation in low-stage intraocular retinoblastoma. J Clin Oncol. 2000;18:2881-7.

16. Kingston JE, Hungerford JL, Madreperla SA, Plowman PN. Results of combined chemotherapy and radiotherapy for advanced intraocular retinoblastoma. Arch Ophthalmol. 1996;114:1339-43.

17. Rodriguez-Galindo C, Wilson MW, Haik BG, et al. Treatment of intraocular retinoblastoma with vincristine and carboplatin. J Clin Oncol. 2003;21:2019-25.

18. Shields CL, Honavar SG, Meadows AT, et al. Chemoreduction plus focal therapy for retinoblastoma: factors predictive of need for treatment with external beam radiotherapy or enucleation. Am J Ophthalmol. 2002;133:657-64.

19. Kingston JE, Hungerford JL, Madreperla SA, et al. Results of combined chemotherapy and radiotherapy for advanced intraocular retinoblastoma. Arch Ophthalmol. 1996;114:1339-43.

20. Bhurgri Y, Bhurgri $\mathrm{H}$, Usman A, et al. Epidemiology of ocular malignancy in Karachi. Asian Pac J Cancer Prev. 2003;4:352-7.

21. Cancer incidence in the five continents. Vol.VIII. Parkin DM, Whelan SL, Ferlay J, Teppo L, Thomas DB, editors. Lyon: IARC Scientific Publication No. 155; 2002.

22. Bhurgri Y, Muzaffar S, Ahmed R, et al. Retinoblastoma in Karachi, Pakistan. Asian Pac J Cancer Prev. 2004:5:159-63.

23. Broaddus E, Tophan A, Singh AD. Incidence of retinoblastoma in the United States: 1975-2004. Br J Ophthalmol. 2009;83:21-3.

24. Bonanomi MT, Almeida MT, Cristofani LM, Odone Filho V. Retinoblastoma: a three-year-study at a Brazilian medical school hospital. Clinics (Sao Paulo). 2009;64:427-34.

25. Abramson DF, Frank CM, Susman M, Whalen MP, Dunkel IJ, Boyd NW 3rd. Presenting signs of retinoblastoma. J Pediatr. 1998;132:505-8.

26. Shields JA, Shields CL. Current management of retinoblastoma. Mayo Clin Proc. 1994;69:550-6.

27. Imhof SM, Moll AC, Schouten-van Meeteren AY. Stage of presentation and visual outcome of patients screened for familial retinoblastoma: nationwide registration in the Netherlands. $\mathrm{Br} \mathrm{J}$ Ophthalmol. 2006;90:875-8.

28. Gündüz K, Günalp I, Yalçindag N, et al. Causes of chemoreduction failure in retinoblatoma and analysis of associated factors leading to eventual treatment with external beam radiotherapy and enucleation. Ophthalmology. 2004;111:1917-24. 